\title{
A PEDAGOGIA DA EDUCAÇÃO INFANTIL CONSTRUÍDA NO COTIDIANO: IDEAIS, CONCEPÇÕES, TENSÕES, DESAFIOS E POSSIBILIDADES
}

\author{
Maria das Graças Oliveira
}

\section{RESUMO}

A atual conjuntura da Educação Infantil no Brasil denota, cada vez mais, a necessidade de produção de saberes acerca da pedagogia que se delineia no cotidiano das instituições públicas de ensino do país. Desse modo, perguntas são postas a todo instante sobre esses saberes pedagógicos, como: quais são as possibilidades existentes nas práticas pedagógicas desenvolvidas no dia a dia com as crianças que legitimam o seu direito a uma educação coletiva de qualidade? Outra questão emerge dessa primeira: quais são as limitações existentes nessas práticas que dificultam o cumprimento do objetivo de consolidar esse direito das crianças, para que elas possam viver as suas infâncias em contextos que respeitem as suas especificidades? Neste artigo, serão abordadas essas duas questões a partir das análises dos dados de uma pesquisa de doutorado realizada em duas creches públicas, na cidade de Belo Horizonte, Minas Gerais. Para tanto, será utilizada a abordagem da sociologia da infância, que nos permite ver as crianças, as professoras e as famílias como coautoras dos processos pedagógicos na construção da pedagogia da infância, cotidianamente, nas relações e interações de uma com as outras. As práticas educativas desenvolvidas com crianças de zero a três anos de idade, as tensões, os desafios e os embates entre esses atores sociais, na creche pública, também serão aqui descritos. Os resultados mostram que se delineia, nesse contexto, uma pedagogia participativa permeada por contradições acerca das seguintes concepções: da função da creche, da educação familiar na educação coletiva e dos cuidados à criança na creche pública.

Palavras-chave: Pedagogia da infância. Cotidiano. Participação

Universidade Federal de Campina Grande UFCG/PB, email: gracaeieduc@ terra.com.br

\section{ABSTRACT}

The current situation of Children Education in Brazil increasingly denotes the necessity to produce knowledge on the pedagogy regarding the daily life of public institutions of education in the country. In this sense, there are questions to be made 
about this pedagogical knowledge at all times, such as: what are the existing possibilities in the teaching practices developed day-by-day with children that affirm their right to a quality collective education? From this question emerges another: what are the existing limitations in these practices hampering the assurance of this right, so that the children may live their childhood in respectful conditions to their peculiarities? In this article, those two questions will be approached from the data analysis of a doctoral research carried out in two public daycares in the city of Belo Horizonte, Minas Gerais. For this purpose, The Childhood Sociology approach will be employed, which allows us to see the children, the teachers and the families as coauthors of the teaching processes in the construction of the childhood pedagogy, in their relationships and interactions with each other in the daily living. The teaching practices developed with 0-to-3 year old children, the tensions, the challenges and the conflicts between these social actors at the public daycare will also be here descripted. The results demonstrate that, in this context, a participative pedagogy takes shape, permeated by contradictions around the following conceptions: the role of the daycares, of the family in the collective education, and of children care at the public daycares.

Keywords: Childhood Pedagogy; Daily Life; Participation.

\section{INTRODUÇÃO}

O limiar do século XXI trouxe consigo a emergência da consolidação de uma pedagogia da infância que atendesse aos direitos das crianças e à nova concepção de criança, de sua educação e de seus cuidados em instituições de educação infantil, especificamente as creches e as pré-escolas. Em primeiro lugar, o direito à educação pública e de qualidade é o princípio almejado pelas postulações da política educacional brasileira, referendada pelas legislações federal e municipal. Entre elas, podemos citar a Lei de Diretrizes e Bases da Educação Nacional - LDB 9.394/96 e as Diretrizes Curriculares Nacionais para a Educação Infantil - DCNEI/2009.

Em segundo lugar, temos as contribuições da sociologia da infância, cujos princípios norteadores delineiam as crianças como sendo atores sociais. Estudiosos como Plaisance (2004), Sirota (2001) e Montandon (2001) apresentam, na sociologia da infância, o conceito de criança como sendo um sujeito social. Nessa condição, as crianças, inclusive os bebês, são sujeitos com participação ativa em seus processos educativos, os quais se dão por meio das negociações que elas realizam com as pessoas adultas e com as outras crianças, com as quais convivem. A sociologia da infância rompe, assim, com o conceito de educação, desenvolvido por Émile Durkheim, à medida que constrói a noção da educação da criança pequena como 
sendo uma ação interativa. Isso é, a criança desempenha um papel ativo "na construção do ser social por meio de múltiplas negociações com seus próximos e, ao mesmo tempo, na construção da identidade do sujeito" (PLAISANCE, 2004, p. 225), diferentemente do papel passivo que lhe era atribuído na perspectiva de Durkheim (1987), em uma educação determinada amplamente pela ação do adulto.

No processo de educação dos homens, surge a necessidade de se pensar nos princípios e nos valores que norteiam esse caminho educativo, o qual pode acontecer em vários lugares sociais e em diversos contextos. A escola, na atualidade, é um dos espaços dedicados pela sociedade à educação dos homens, e a educação infantil é uma modalidade escolar que atende às crianças de zero a cinco anos de idade e que ganha relevância no cenário educativo contemporâneo. A educação infantil dá-se em contextos educativos nas modalidades creche (para crianças de zero a três anos de idade) e pré-escola (para aquelas com idade entre quatro a cinco anos). Nessa perspectiva, a função precípua do atendimento às crianças nessas modalidades de ensino é a promoção do seu desenvolvimento pleno, como determinam as Diretrizes Curriculares Nacionais para a Educação Infantil:

A proposta pedagógica das instituições de Educação Infantil deve ter como objetivo garantir à criança acesso a processos de apropriação, renovação e articulação de conhecimentos e aprendizagens de diferentes linguagens, assim como o direito à proteção, à saúde, à liberdade, à confiança, ao respeito, à dignidade, à brincadeira, à convivência e a interação com outras crianças (BRASIL, 2009).

Pode-se dizer que essa legislação institui, nas instituições de educação infantil, a concepção de criança como sendo um ator social de direitos, portanto um coautor de seu processo de inserção no mundo da cultura, seja a cultura familiar, seja a cultura da creche ou a cultura considerada socialmente legítima. Isso denota a elaboração de propostas pedagógicas fundamentadas em uma referência teórica acerca da criança e de suas linguagens, aliada à observação das crianças, feita pelos professores, em suas relações e interações sociais e culturais na instituição de educação infantil. E, para essa tarefa, é fundamental que eles sejam conhecedores das crianças com as quais atuam e as respeitem como cidadãs de direito, construtoras de cultura na relação que estabelecem com o adulto.

Este artigo parte da premissa de que, nas creches públicas, há uma pedagogia da infância em construção no cotidiano. Ou seja, é no processo de educação e de cuidados às crianças, delineado pela ação dos atores sociais envolvidos, as crianças, as professoras e as famílias, e pelo confronto entre os seus saberes, os seus 
conhecimentos e as suas concepções, que essa pedagogia se configura. Além disso, ela ainda apoia-se no pressuposto de que as ressignificações e as apropriações que esses atores fazem das prescrições da legislação educacional em vigor são também "fios" constitutivos dessa trama cotidiana da pedagogia da infância.

Dessa forma, pode-se indagar: o que é, afinal, a pedagogia da infância? Em que ela se fundamenta? Essas questões desafiadoras apresentam-se como pano de fundo no contexto da educação infantil contemporânea. Acredito que o desvelamento das práticas pedagógicas desenvolvidas no cotidiano das instituições de educação infantil pode contribuir, sobremaneira, para que as pedagogias da infância, construídas pelos atores sociais nos contextos reais das creches, tenham visibilidade e possam desencadear reflexões profícuas acerca dessa temática, e para que sejam vislumbradas possibilidades para uma consolidação da pedagogia da infância que atenda aos princípios educativos específicos para as crianças na faixa etária de zero a três anos.

Essas considerações permitem levantar outras indagações: qual a pedagogia que melhor atende a esses princípios? Quais as condições reais existentes no cotidiano das creches e pré-escolas para a criação e o desenvolvimento da pedagogia da infầncia?

São essas as questões que nortearão este texto, o qual está organizado da seguinte forma: inicialmente, será discutida a pedagogia da infância conceitualmente e os valores emanados dessa perspectiva na educação e nos cuidados às crianças nas instituições de ensino; em seguida, será analisada a construção da pedagogia nas creches públicas da cidade de Belo Horizonte, Minas Gerais, a partir das práticas pedagógicas das professoras da Educação Infantil; e por fim, serão apresentadas as considerações finais deste estudo.

\section{A PEDAgOgia dA EDUCAÇÃO INFANTIL: UMA ABORDAGEM NA PERSPECTIVA DO DIREITO DAS CRIANÇAS}

A temática da pedagogia da infầncia torna-se cada vez mais relevante no campo da Educação Infantil. Professores dessa modalidade de ensino, pesquisadores, famílias das crianças e gestores buscam a construção e o desenvolvimento de uma pedagogia que atenda às crianças em suas especificidades nas instituições de Educação Infantil. Nesse debate, as contribuições de Oliveira (2007) são significativas, pois ela argumenta que, historicamente, os pedagogos buscam modos 
alternativos para fazer pedagogia, suplantando a pedagogia transmissiva que, no seu fazer pedagógico, "ignora os direitos da criança a ser vista como competente e a ter espaço de participação" (OLIVEIRA, 2007, p. 13). Desse modo, a autora defende a necessidade da construção de uma pedagogia da participação, pois:

Uma pedagogia centrada na práxis de participação procura responder à complexidade da sociedade e das comunidades, do conhecimento, das crianças e de suas famílias, com um processo interativo de diálogo e confronto entre crenças e saberes, entre saberes e práticas, entre práticas e crenças, entre esses pólos em interação e os contextos envolventes (OLIVEIRA, 2007, p. 15).

O desenvolvimento de uma pedagogia participativa, na perspectiva da autora, abrange três tarefas básicas: a construção de contextos educativos nos quais haja múltiplas possibilidades e que o conhecimento seja construído de forma participativa; a centralidade nas relações, uma vez que esse modo pedagógico pode ser definido como sendo o espaço para a interação e a escuta; e por fim, o diálogo com a história, aderindo-se a um fazer pedagógico de forma reflexiva e compartilhada, a fim de contribuir para a construção de conhecimento sobre o modo de fazer adotado (OLIVEIRA, 2007).

No contexto da Educação Infantil, o debate acerca da pedagogia da infância tem como foco a especificidade das ações de cuidado e de educação da criança de zero a cinco anos de idade, de forma integrada. Sendo assim, torna-se relevante atribuir à Educação Infantil características que a distingam do Ensino Fundamental. $\mathrm{Ou}$ seja, buscar uma identidade própria para o atendimento à infância, em instituições de educação coletiva, fora do âmbito familiar. Pode-se perceber também essa argumentação em autores como Faria (2007), Bujes (2001) e Plaisance (2004), os quais defendem que a Educação Infantil não se configura como um espaço de "escolarização precoce" das crianças. A escolarização precoce, nessa perspectiva, refere-se às atividades que envolvem lápis e papel, alfabetização e a pouca experiência das crianças com a brincadeira, entre outras.

A pedagogia da infância "constitui-se de um conjunto de fundamentos e indicações de ação pedagógica que tem como referência as crianças e as múltiplas concepções de infầncia em diferentes espaços educacionais" (BARBOSA, 2010). A partir dessa definição, a autora descreve algumas características dessa pedagogia, como, por exemplo: compreende que as ações educativas devem considerar as crianças e os seus contextos sociais; toma as crianças como seres humanos, históricos, capazes de múltiplas relações, produtores de formas culturais próprias 
construídas com seus pares; afirma a infância como categoria geracional, social, histórica e geograficamente construída, permeada por relações de classe, gênero, religião e etnia; admite a criança como um sujeito de direitos. A autora argumenta ainda que:

\footnotetext{
A afirmação das crianças como sujeitos de direitos exige a definição de indicativos pedagógicos que possibilitem às crianças a experiência da infância de forma a tomar parte em projetos educacionais fundados na democracia, na diversidade, na participação social, a partir de práticas educativas que privilegiem as relações sociais entre todos os segmentos envolvidos (crianças, famílias e educadores) (BARBOSA, 2010).
}

Podemos dizer, a partir dessas considerações, que a emergência da pedagogia da infância no contexto atual demanda que haja, nos processos pedagógicos, a valorização dos atores sociais - os professores, as crianças e suas famílias -. Isso porque a elaboração de uma pedagogia da infância participativa implica na necessidade do estabelecimento de relações mais próximas entre os envolvidos. $\mathrm{Ou}$ seja, uma nova ética emerge desse contexto: aquela que acredita na potencialidade das crianças e que oportuniza a elas experiências educativas em que sejam coautoras no cotidiano das instituições de ensino e referência para as tomadas de decisões, a partir de reflexões fundamentadas nos aportes teóricos do campo da infância. Desse modo, buscar nas linguagens das crianças a inspiração para a criação de espaços educativos e de cuidados competentes e adequados para suas diferentes faixas etárias e considerar a diversidade social, cultural e histórica, delas e de suas famílias contribui, significativamente para a construção de propostas educacionais que atendam às especificidades das crianças na creche e na pré-escola.

\section{O PERCURSO DA PESQUISA}

A pesquisa de abordagem qualitativa foi realizada em duas Unidades Municipais de Educação Infantil (UMEIs), localizadas em Belo Horizonte, Minas Gerais. Os dados da pesquisa foram coletados por meio de observação do cotidiano dessas creches públicas, de realização de entrevistas semiestruturadas com as professoras, as famílias e as coordenadoras, e pela análise documental. A análise dos dados baseou-se na perspectiva da análise de conteúdo, que se constitui em "um conjunto de técnicas de análise das comunicações”, ou seja, há uma busca pelo rigor e pela necessidade de descobrir, de adivinhar e de compreender as comunicações que estão sendo alvo das análises (BARDIN, 2000, p. 31-32). Essa técnica pode ser, 
também, segundo o autor, uma análise dos significados ou dos significantes das comunicações em questão. Os dados coletados foram submetidos a várias leituras para o estabelecimento de categorias de análise e, posteriormente, foram organizados e categorizados a partir de sua interpretação. Buscava-se, dessa maneira, apreender os modos pelos quais os professores, as crianças e suas famílias construíam a relação entre si, no cotidiano das creches públicas, e os possíveis consensos, conflitos e desafios advindos dessa relação.

\section{ENTRELAÇANDO CONCEPÇÕES NA CONSTRUÇÃO COTIDIANA DA PEDAGOGIA DA CRECHE PÚBLICA: EDUCAÇÃO, CUIDADO, CIDADANIA E CULTURA}

No ano de 2004, são criadas as Unidades Municipais de Educação Infantil (UMEIs) em Belo Horizonte. Inaugura-se, desse modo, o atendimento público às crianças de zero a três anos de idade na cidade. Trata-se de um "novo tempo" em que as atenções dos gestores, dos professores, das famílias e da comunidade em geral têm como foco este desafio emergente: os cuidados e a educação coletiva das crianças na tenra idade, nessa instituição pública de ensino. Ou seja, pensar a organização do espaço físico e dos tempos de forma a favorecer as interações entre as crianças, suas famílias, o meio sociocultural e os adultos. Além disso, surgem os Educadores Infantis (atualmente professores para a Educação Infantil), conquista de uma década de lutas pelo reconhecimento da docência nas UMEIs. Esse novo profissional chega às UMEIs trazendo experiências de outras áreas de atuação, tais como: o Ensino Fundamental, a saúde e a Educação Infantil na rede particular de ensino. Atraídos pela estabilidade profissional, a qualidade do espaço físico e a materialidade, os educadores buscam conhecer as crianças, as famílias e o modus operandi da prática educativa com os bebês. Tais novidades desencadearam tessituras diversas no campo da Educação Infantil mineira.

A criação da carreira do Educador Infantil trouxe também, para o cenário da educação pública, uma organização "inovadora" de trabalho para as creches, de maneira que essa demanda a regência múltipla das turmas. Nessa organização, para se cumprir a carga horária diária com as crianças (das $7 \mathrm{~h}$ às $17 \mathrm{~h} 30 \mathrm{~min}$ ) na instituição, os tempos, nas turmas, são compartilhados por seis professoras da seguinte forma: no horário da manhã (de $7 \mathrm{~h}$ às $11 \mathrm{~h} 30 \mathrm{~min}$ ), duas professoras; no horário intermediário (de 9h30min às 13 h30min), outra dupla; e por fim, à tarde (de 
$13 \mathrm{~h}$ às $17 \mathrm{~h} 30 \mathrm{~min}$ ), assumiam outras duas professoras. A transição era sempre feita pelas professoras do turno intermediário, as quais repassavam, brevemente, os aspectos daquela rotina que elas consideravam importantes para as outras professoras que chegavam, tais como: crianças que haviam se alimentado mal ou que estavam doentes, crianças que sofreram quedas, que se machucaram, e, até mesmo, sobre os projetos que estavam pensando em desenvolver com a turma. Um caderno de nota e as anotações em um quadro branco também auxiliavam na comunicação, que, em algumas situações, se mostravam ineficientes.

Essa pluralidade de relações interpessoais e pedagógicas, ocasionada por essa forma de regência, teve implicações importantes na construção da pedagogia nas UMEIs pesquisadas. Uma pedagogia que, de acordo com os princípios estabelecidos por seus Projetos Políticos Pedagógicos, centrava-se nas crianças e buscava articulação com suas famílias no cotidiano. Tanto a ação educativa quanto os cuidados das crianças fundamentavam-se prioritariamente nas linguagens infantis. Essas linguagens, para Lima (2003), envolvem o corpo, o som, o movimento, o humor e as emoções, a vivência do tempo e do espaço, constituindo-se como recursos da função simbólica necessária para que as pessoas possam construir e utilizar as linguagens. Estavam presentes, nas práticas docentes dessas UMEIs, as linguagens da Música, da Arte e a linguagem Corporal. Assim, a pedagogia da infância delineava-se por meio da promoção de espaços para a exploração, pelas crianças, dos objetos, das coisas, da natureza, e para as interações entre adultos e crianças nas brincadeiras, nas ações de cuidado com a higiene e a alimentação, e para o contato dos pequenos com a produção cultural para a infância (artefatos musicais e teatrais, brinquedos industrializados, livros de literatura e outros).

\section{OS RITMOS DOS TEMPOS E DOS ESPAÇOS NOS COMPASSOS DA MÚSICA E DA BRINCADEIRA}

A organização dos tempos e dos espaços nas UMEIs analisadas teve como características básicas a versatilidade e o dinamismo. Pois, assim, as professoras concebiam essa ação: "Olha, a rotina do berçário muda muito. Cada dia é um dia diferente; não dá para falar: tal hora nós vamos fazer isso, depende muito de como estão os bebês [...]” (Extrato do Diário de Campo, junho de 2008). Pode-se dizer que havia, por parte delas, uma atitude de observação, de maneira a conhecer as crianças naquele espaço educativo. Dessa forma, os gostos, as reações e preferências dos 
meninos e das meninas tornaram-se conhecidos pelas professoras. E, a partir da análise que faziam dessas particularidades infantis, buscavam organizar os tempos e os espaços para que as crianças experimentassem várias formas de expressão corporal e expressassem as suas linguagens no espaço da creche, na relação com os adultos e com as outras crianças.

O fragmento abaixo, nota da observação das atividades desenvolvidas com as crianças em uma das UMEIs pesquisadas, mostra como esses atores sociais tecem os seus lugares sociais e as suas experiências educativas.

O tempo pela manhã parece passar mais devagar. As atividades desenrolam-se uma a uma, regidas pela orquestra da música que toca no aparelho de som. No começo do dia, canções mais tranquilas para convidar professoras, crianças e pesquisadora (eu) para explorar o espaço e as coisas que nele existem. Um tatame e muitos brinquedos coloridos que se revezam passando pelas mãos curiosas dos meninos, que convidam as meninas para brincarem. Não basta tirar os brinquedos da bacia, eles precisam experimentar esse espaço tão complicado para entrar e brincar. Aprender que a bola é um brinquedo coletivo é muito rápido, e eles alegram-se quando o outro, seja adulto ou criança, aceita o convite para jogar e pegar a bola. Os carrinhos de bebês colocados na sala significam que é chegada a hora do passeio no parquinho e de tomar banho de sol. Esse é o espaço para brincar no balanço, correr atrás das bolinhas de sabão, ou de simplesmente engatinhar e explorar o pátio. Mais um pouco e a música muda. É um acalanto, avisando que é hora da mamadeira, das trocas de fraldas que se fizerem necessárias e do descanso. Os carrinhos balançam devagar, um a um, eles (os bebês) entregam-se ao sono. Uns dormem mais tempo, outros menos tempo, e, com isso, o dia segue. Ao acordarem, é hora do banho, da brincadeira no banheiro e do almoço. Para aqueles que não dormem após o almoço, o final da manhã e a chegada da tarde são movimentados. A música convida-os para dançarem junto com a professora que chega. A brincadeira é mais agitada, são desafios colocados pela professora, instigando a ação para resolver o que fazer: dançar, explorar uma caixa de papelão, arrastar para pegar os brinquedos, brincar com o boneco de pano. Aos poucos, os que acordam se juntam ao grupo e continuam a brincar (Extrato do Diário de Campo, junho de 2008).

A docência compartilhada pelas seis professoras traz, para as crianças, essa possibilidade de terem experiências diferenciadas no espaço da creche. As docentes, ao desenvolverem as suas práticas a partir do princípio de escutar, de dialogar com as crianças e de dar espaço para que sejam ativas e colaboradoras nas atividades, o fazem a partir desse olhar para as crianças, dos saberes de sua formação e de suas características pessoais, como, por exemplo: a seleção musical e os ritmos dados por cada uma delas às atividades. Essa dinâmica requer que essas profissionais desenvolvam habilidades para negociar e discutir as suas concepções com as outras colegas e para analisar e negociar com as crianças sob uma perspectiva antropológica, com o intuito de observar como se apresentam no cotidiano. 
Dessa observação da ação pedagógica com as crianças na UMEI, pode-se depreender que uma pedagogia participativa na creche demanda o reconhecimento, por parte do professor, das crianças como sendo cidadãs de direito, acreditando nas possibilidades reais dessas crianças no espaço de educação coletiva.

No contexto atual da emergência de uma pedagogia da infância de cunho participativo, os pressupostos de Loris Malaguzzi, educador italiano, podem contribuir de forma significativa, pois ele defende o protagonismo das crianças, dos(as) professores(as) e das famílias nos processos educativos e de cuidados, na Educação Infantil. Nessa perspectiva, em uma carta redigida por Malaguzzi, em 1993, são apresentados os direitos dos pais, dos profissionais e das crianças como complementares: aos pais, é atribuído o direito de participação ativa e a adesão aos princípios educativos da instituição de ensino onde suas crianças estão matriculadas; aos profissionais, os direitos referem-se ao seu papel ativo na elaboração e no desenvolvimento de conteúdos, metodologias, projetos e outros, juntamente com a coordenação pedagógica; e às crianças, os direitos dizem respeito ao seu reconhecimento como sujeitos de direitos, portadores e construtores de culturas e de suas identidades nas relações com seus coetâneos e com os adultos. Pode-se dizer que se trata de uma perspectiva coletiva de Educação Infantil, que busca, na ação dos sujeitos, os caminhos para que as crianças tenham garantidos os seus direitos, principalmente o de ser criança em sua totalidade, na instituição de educação coletiva, fora de sua família.

Nessa organização investigada, notou-se que, entre as professoras responsáveis pelas turmas, existia o consenso de que a criança tinha centralidade no processo educativo e de que era necessário buscar formas de compartilhar com as famílias essa educação. Entretanto, despontava nelas a insegurança sobre a legitimidade teórica da prática pedagógica adotada. Por vezes, as educadoras expressavam o sentimento de que precisavam buscar alguém para dialogar sobre suas experiências na docência com os bebês. Elas buscavam, na literatura acadêmica, as respostas sobre as suas dúvidas, mas destacavam que eram poucas as opções disponíveis que abordavam a educação e os cuidados na creche, na perspectiva da prática cotidiana. 


\section{CONSIDERAÇÕES FINAIS}

A observação das práticas educativas das professoras da Educação Infantil nas UMEIs analisadas possibilitou a aproximação das concepções e das estratégias utilizadas pelas docentes na elaboração e no desenvolvimento dos projetos pedagógicos com as crianças menores de três anos. E ainda, possibilitou conhecer as diferentes formas de interação entre os atores sociais - professoras, crianças e suas famílias -, no cotidiano das instituições de ensino, e os conflitos gerados nessa interação, e também as respostas das crianças às propostas de atividades das professoras.

Essa possibilidade de traçar caminhos em conjunto e a partir das linguagens das crianças corrobora com a perspectiva da pedagogia da participação, em que a criança é vista como sendo um sujeito de direitos, capaz de participar ativamente na sua inserção no universo da cultura da creche.

Desse modo, argumenta-se que a análise dessas práticas pedagógicas contribui para que elas tenham visibilidade no cenário da Educação Infantil, havendo, além disso, a necessidade de realização de outras pesquisas sobre a temática para ampliação dos debates e do conhecimento a respeito das tensões e possibilidades da pedagogia da infância no cotidiano das creches públicas, tendo em vista que a educação coletiva e os cuidados das crianças, nessas instituições, são uma realidade no cenário educacional brasileiro.

\section{REFERÊNCIAS}

BARBOSA, M. C. S. Pedagogia da infância. In: OLIVEIRA, D. A.; DUARTE, A. M. C.; VIEIRA, L. M. F. DICIONÁRIO: trabalho, profissão e condição docente. Belo Horizonte: UFMG/Faculdade de Educação, 2010. 1 CD-ROM.

BARDIN, Laurence. Análise de conteúdo. Tradução de Luís Antero Reto, Augusto Pinheiro. Lisboa: Edições 70, 2002.

BRASIL. Ministério da Educação e do Desporto. Lei n. 9.394/96, de 20 de dezembro de 1996. Brasília: LDB, 1996.

BRASIL. Ministério da Educação e do Desporto. Conselho Nacional da Educação. Secretaria de Educação Básica. Diretrizes curriculares nacionais para a educação infantil. Brasília, DF: MEC, SEB, 2009. 
BUJES, Maria Isabel Edelwiss. Escola infantil: pra que te quero? In: CRAIDY, Carmem; KAERCHER, Gládis (Orgs.). Educação infantil, pra que te quero?. Porto Alegre: Artmed, 2001.

DURKHEIM, Émile. Sociologia, educação, moral. Porto, Portugal: Res-Editora, 1987.

LIMA, Elvira Souza. A criança pequena e suas linguagens: grupo de estudos do desenvolvimento humano. São Paulo: Editora Sobradinho, 2003.

MONTANDON, Cléopátre. Sociologia da infância: balanço dos trabalhos em língua inglesa. Cadernos de Pesquisa, São Paulo, n. 112, p. 33-60, 2001.

OLIVEIRA, Júlia Formosinho. Pedagogia(s) da infância: reconstruindo uma práxis de participação. In: OLIVEIRA, Júlia Formosinho; KISHIMOTO, Tizuko Morchida; PINAZZA, Mônica Appezzato (Orgs.). Pedagogia(s) da infância: dialogando com o passado: construindo o futuro. Porto Alegre: Artmed, 2007.

PLAISANCE, Eric. Para uma sociologia de pequena infância. Educação e Sociedade, Campinas, n. 86, p. 219-242, 2004.

SIROTA. Regine. Emergência de uma sociologia da infância: evolução do objeto e do olhar. Cadernos de Pesquisa, São Paulo, n. 112, p. 7-31, 2001. 